\title{
Mode I Fracture Toughness of a Small-Grained Silicon Nitride: Orientation, Temperature, and Crack Length Effects
}

\author{
Rodney W. Trice ${ }^{*}$, and John W. Halloran ${ }^{\star}$ \\ Materials Science and Engineering Department, University of Michigan, Ann Arbor, Michigan 48109-2136
}

\begin{abstract}
The Mode I fracture toughness $\left(K_{\mathrm{IC}}\right)$ of a small-grained $\mathrm{Si}_{3} \mathrm{~N}_{4}$ was determined as a function of hot-pressing orientation, temperature, testing atmosphere, and crack length using the single-edge precracked beam method. The diameter of the $\mathrm{Si}_{3} \mathrm{~N}_{4}$ grains was $<0.4 \mu \mathrm{m}$, with aspect ratios of $2-8 . K_{I C}$ at $25^{\circ} \mathrm{C}$ was $6.6 \pm 0.2$ and $5.9 \pm 0.1 \mathrm{MPa} \cdot \mathrm{m}^{1 / 2}$ for the $\mathrm{T}-\mathrm{S}$ and $\mathrm{T}-\mathrm{L}$ orientations, respectively. This difference was attributed to the amount of elongated grains in the plane of crack growth. For both orientations, a continual decrease in $K_{\mathrm{IC}}$ was observed through $1200^{\circ} \mathrm{C}$, to $\sim 4.1$ $\mathrm{MPa} \cdot \mathrm{m}^{1 / 2}$, before increasing rapidly to $7.5-8 \mathrm{MPa} \cdot \mathrm{m}^{1 / 2}$ at $1300^{\circ} \mathrm{C}$. The decrease in $K_{\mathrm{IC}}$ through $1200^{\circ} \mathrm{C}$ was a result of grain-boundary glassy phase softening. At $1300^{\circ} \mathrm{C}$, reorientation of elongated grains in the direction of the applied load was suggested to explain the large increase in $K_{\mathrm{IC}}$. Crack healing was observed in specimens annealed in air. No $\boldsymbol{R}$-curve behavior was observed for crack lengths as short as $300 \mu \mathrm{m}$ at either $25^{\circ}$ or $1000^{\circ} \mathrm{C}$.
\end{abstract}

\section{Introduction}

$\mathrm{M}$ ANY ceramics demonstrate increasing fracture toughness with increasing crack length. ${ }^{1-4}$ This $R$-curve behavior arises because of the interactions of the microstructure behind the crack tip in the wake region. ${ }^{5}$ The degree to which $R$-curve behavior is observed in $\mathrm{Si}_{3} \mathrm{~N}_{4}$ is dependent upon the microstructure, with high aspect ratio $\beta-\mathrm{Si}_{3} \mathrm{~N}_{4}$ grains providing the most benefit. ${ }^{6-9}$ The Mode I fracture toughness $\left(K_{\mathrm{IC}}\right)$ of $\mathrm{Si}_{3} \mathrm{~N}_{4}$ with cracks $>1 \mathrm{~mm}$ generally ranges from 5.5 to 11 $\mathrm{MPa} \cdot \mathrm{m}^{1 / 2} \cdot 6,10$

The orientation and size of the $\mathrm{Si}_{3} \mathrm{~N}_{4}$ grains also influence toughness. Ohji et al. ${ }^{10}$ demonstrated that, when fibrous $\beta-\mathrm{Si}_{3} \mathrm{~N}_{4}$ grains span the crack wake, improved toughening results. An investigation ${ }^{11}$ of the effect of grain size on toughness, keeping aspect ratio constant, revealed a general increase in $K_{\mathrm{IC}}$, from 4.2 to $6.2 \mathrm{MPa} \cdot \mathrm{m}^{1 / 2}$, as grain size increased from 7 to $45 \mu \mathrm{m}$.

There are four toughening mechanisms relevant to $\mathrm{Si}_{3} \mathrm{~N}_{4}$. These include crack deflection, grain pull out, elastic bridging, and frictional grain bridging. Crack deflection is more prominent in $\mathrm{Si}_{3} \mathrm{~N}_{4}$ with diameters $>1 \mu \mathrm{m} .{ }^{7}$ Smaller diameter grains tend to be cut by the propagating crack. Crack deflection is also favored above the glass transition temperature of the amorphous grain-boundary phase. ${ }^{12,13}$ The softened glassy phase provides an easy crack path, resulting in intergranular fracture.

The remaining three types of toughening mechanismsgrain pull out, elastic bridging, and frictional grain bridging-

J. J. Petrovic — contributing editor

Manuscript No. 190139. Received May 29, 1998; approved February 8, 1999. Supported by DARPA/ONR under Contract No. 0014-95-0302.

Based in part on thesis submitted by R. W. Trice for the Ph.D. degree in materials science and engineering, University of Michigan, Ann Arbor, MI, 1997.

Member, American Ceramic Society.

${ }^{\dagger}$ Now at Northwestern University, Evanston, IL. tend to shield the crack tip as it extends through the material because of microstructure interactions in the wake of the crack. The grain pull out mechanism is favored for smaller diameter grains ${ }^{7}$ and for tests at higher temperatures. ${ }^{13}$ In the elastic bridging mechanism, an elongated grain sustains some of the load being applied at the crack tip before ultimately being cut. ${ }^{7}$ This mechanism is favored for larger diameter grains. Frictional bridges, resulting from contact points between the upper and lower faces of the opened crack, are favored when crack deflection and grain pull out occur.

Current research focused on determining the $K_{\mathrm{IC}}$ of a smallgrained $\mathrm{Si}_{3} \mathrm{~N}_{4}$ using the single-edge precracked beam (SEPB) method. ${ }^{14-16}$ Both 6 wt $\% \mathrm{Y}_{2} \mathrm{O}_{3}$ and $2 \mathrm{wt} \% \mathrm{Al}_{2} \mathrm{O}_{3}$ were added as sintering aids. The effect of hot-pressing orientation, temperature, crack length, and environment on $K_{\mathrm{IC}}$ was determined. Test temperatures included $25^{\circ}$, and $800^{\circ}$ through $1300^{\circ} \mathrm{C}$. The existence of $R$-curve behavior was investigated using the Steinbrech method ${ }^{1,17}$ of notching already precracked specimens, removing the crack wake. The testing atmosphere was either air or nitrogen.

\section{Experimental Procedure}

\section{(1) Billet Fabrication}

Monolithic $\mathrm{Si}_{3} \mathrm{~N}_{4}$ billets were formed by thermoplastic molding and densified by hot-pressing. Beginning with $92 \mathrm{wt} \%$ $\mathrm{Si}_{3} \mathrm{~N}_{4}$ powder (SN-E-10, UBE Industries, Yamaguchi, Japan), 6 wt $\% \mathrm{Y}_{2} \mathrm{O}_{3}$ (99.9\% pure; REaction, Johnson Matthey, Inc., West Chester, PA), and $2 \mathrm{wt} \% \mathrm{Al}_{2} \mathrm{O}_{3}$ (RC-HP DBM, Malakoff Industries, Richmond, VA), batched powders were ball-milled in ethanol for $48 \mathrm{~h}$ to mix and deagglomerate the starting powder mixture. Approximately 52 vol\% ceramic powder $\left(\mathrm{Si}_{3} \mathrm{~N}_{4}\right.$ and sintering aids) was mixed with poly(ethylene-vinyl acetate), poly(ethylene-ethyl acrylate), and high mineral oil at $150^{\circ} \mathrm{C}$ in a high-shear mixer. Small pieces of the powder/ polymer mixture were cut and warm-pressed into a billet at $150^{\circ} \mathrm{C}$ and $\sim 10-20 \mathrm{MPa}$.

A $98 \mathrm{~h}$ binder burnout step, from $25^{\circ}$ through $700^{\circ} \mathrm{C}$, was conducted in flowing nitrogen to remove the polymer binder from the warm-pressed billet. Next, a $36 \mathrm{~h}$ postbinder burnout heat treatment in flowing air at a temperature of $400^{\circ} \mathrm{C}$ was performed on each billet. Subsequent analysis indicated that billets had $<0.13 \mathrm{wt} \%$ residual carbon.

Following the two burnout steps, billets were hot-pressed (Model HP-50, Thermal Technology, Inc., Santa Rosa, CA) at $1740^{\circ} \mathrm{C}$ under an applied pressure of $25 \mathrm{MPa}$. The heating rate was $\sim 600^{\circ} \mathrm{C} / \mathrm{h}$, and load was not applied until the temperature, measured off the surface of the die with a pyrometer, reached $1200^{\circ} \mathrm{C}$. A $1.75 \mathrm{~h}$ dwell time at temperature was used.

\section{(2) Specimen Fabrication and Testing}

The 4-5 mm thick billets were machined to a thickness of either 3 or $4 \mathrm{~mm}$ by removing equal amounts of material from both sides using diamond-impregnated grinding wheels. Samples were cut using diamond blades (American Diamond Tool, Inc., Buffalo, NY) into the desired sample size, typically $3 \mathrm{~mm} \times 4 \mathrm{~mm} \times 24 \mathrm{~mm}$.

The density of each sample, measured using the immersion 
technique, ${ }^{18}$ was $3.27 \pm 0.05 \mathrm{~g} / \mathrm{cm}^{3}$. The acoustic resonance method $^{19}$ (Grindosonic, J. W. Lemmens, Inc., St. Louis, MO) revealed the modulus to be $312 \pm 1 \mathrm{GPa}$. X-ray diffraction (XRD) of pulverized specimens indicated complete transformation of the starting $\alpha-\mathrm{Si}_{3} \mathrm{~N}_{4}$ powder to $\beta-\mathrm{Si}_{3} \mathrm{~N}_{4}$.

$K_{\text {IC }}$ was determined using the SEPB method. ${ }^{14-16}$ A shallow $0.1 \mathrm{~mm}$ deep notch was cut into the width dimension, near the middle of the beam. A sharp precrack was "popped" into the beam at room temperature via the bridge-indentation method (B-I). The typical $a / W$ ratios were $0.4-0.5$, where $a$ was the average precrack length and $W$ the thickness of the beam (nominally $4 \mathrm{~mm}$ ). The specimen was then loaded into a threepoint $\mathrm{SiC}$ fixture, heated to the desired temperature, stabilized for $10 \mathrm{~min}$, and fractured at a strain rate of $0.1 \mathrm{~mm} / \mathrm{min}$. The fracture load was retrieved, and the initial precrack length was measured by observing the fracture surfaces. A stereo microscope was used to delineate between the precrack and the fractured regions. Crack lengths were made in three locations according to the standard procedure.

$K_{\text {IC }}$ was calculated from the following equations ${ }^{15}$

$$
K_{\mathrm{IC}}=g \frac{P_{\max } S}{B W^{3 / 2}} \frac{3\left(\frac{a}{W}\right)^{1 / 2}}{2\left(1-\frac{a}{W}\right)^{3 / 2}}
$$

where

$$
\begin{aligned}
g & =g\left(\frac{a}{W}\right) \\
& =\frac{1.99-\left(\frac{a}{W}\right)\left(1-\frac{a}{W}\right)\left[2.15-3.93\left(\frac{a}{W}\right)+2.7\left(\frac{a}{W}\right)^{2}\right]}{1+2\left(\frac{a}{W}\right)}
\end{aligned}
$$

where $g$ was a geometric factor based on the average crack length and specimen thickness, $P_{\max }$ the load required for fracture, $S$ the span between the two outer loading pins, and $B$ the width of the beam (nominally $3 \mathrm{~mm}$ ). These equations are valid for $S / W$ ratios between 4 and 5 and $a / W$ ratios between 0.35 and 0.70 . For the current specimen geometry $S=20 \mathrm{~mm}$ and $W=4 \mathrm{~mm}$, resulting in $S / W=5$.

Testing was performed on a screw-driven load frame (Model Instron 4483, Instron Corp., Canton, MA) equipped with a 5 $\mathrm{kN}$ load cell. Material evaluations were made between $25^{\circ}$ and $1300^{\circ} \mathrm{C}$ using a clamshell furnace (Applied Test Systems, Butler, PA). A thermocouple, brought up through the bottom of the furnace, was placed within several millimeters of the sample during testing. Testing was conducted in both air and nitrogen environments. Three replicates each were performed between $25^{\circ}$ and $1000^{\circ} \mathrm{C}$. Between $1100^{\circ}$ and $1300^{\circ} \mathrm{C}$, two replicates each were tested. Stable crack growth prior to fracture was only observed at $1300^{\circ} \mathrm{C}$. At this temperature, $K_{\mathrm{IC}}$ was calculated using the crack length and load just prior to unstable crack propagation.

\section{Results and Discussion}

\section{(1) Microstructure and Texturing}

The two different orientations investigated relative to the hot-pressing direction are defined in Fig. 1. In the T-S orientation, crack growth occurs parallel to the hot-pressing direction, while in the T-L orientation, crack growth occurs perpendicular to the hot-pressing direction.

Figure 2 shows SEM micrographs of plasma-etched samples for both orientations. The orientation of these images relative to the crack propagation direction is shown in Fig. 1. Both
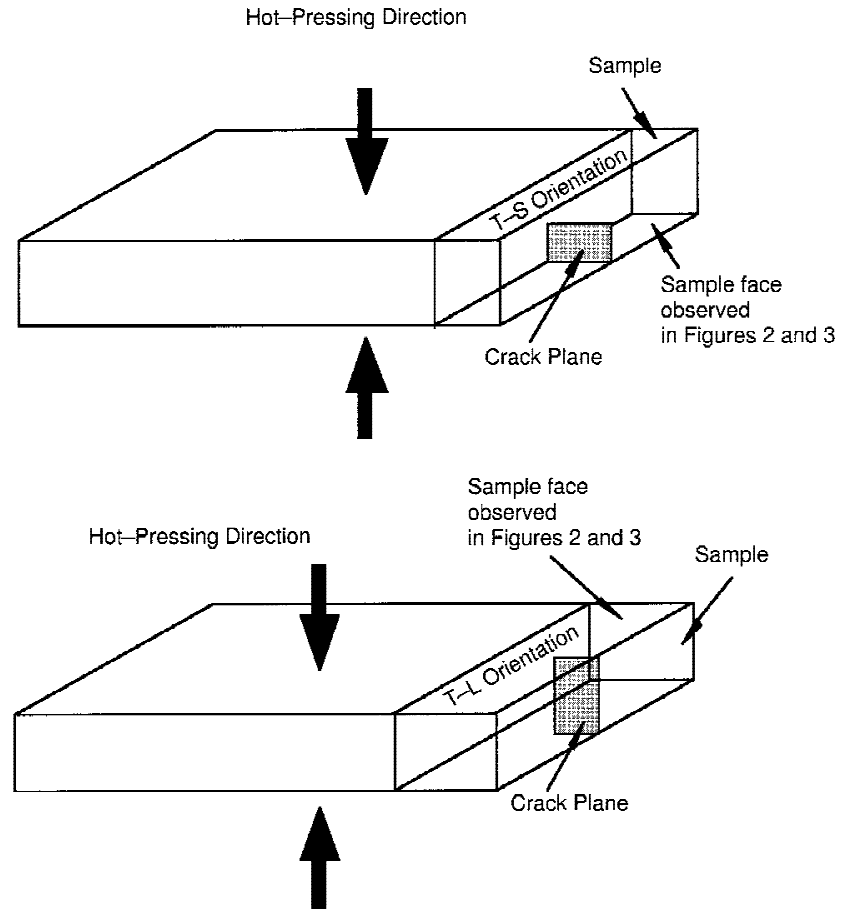

Fig. 1. Schematic indicating two specimen orientations with respect to hot-pressing direction used in the present study. Designations were taken from the ASTM Provisional Standard, C28.01.15

micrographs reveal predominately small grains with apparent diameters of $0.2-0.4 \mu \mathrm{m}$ with a few larger $0.6-1.2 \mu \mathrm{m}$ diameter grains. Of those grains oriented with their long axis parallel to the micrograph, apparent grain lengths vary between 1 and $3 \mu \mathrm{m}$, resulting in an aspect ratio of $\sim 2-8$. More $\mathrm{Si}_{3} \mathrm{~N}_{4}$ grains are oriented lengthwise within the plane of crack growth for the $\mathrm{T}-\mathrm{L}$ orientation as compared to the $\mathrm{T}-\mathrm{S}$ orientation.

$\mathrm{XRD}$ was used to further demonstrate the differences in orientation. The surface represented in Fig. 2 was chosen for analysis. Figure 3 shows XRD patterns from a powder sample, a T-S-oriented sample, and a T-L-oriented sample with intensities normalized to the (1010) peak of $\beta-\mathrm{Si}_{3} \mathrm{~N}_{4} \cdot \mathrm{ZrO}_{2}$ was present because of milling media contamination. The relative intensities of a randomly oriented powder sample of $\beta-\mathrm{Si}_{3} \mathrm{~N}_{4}$ were $100 \%, 99 \%$, and $93 \%$ for the (10) 10$),(10 \overline{1} 1)$, and (2130) planes,${ }^{20}$ respectively. For samples in the T-S orientation, there was a preference for $(10 \overline{1} 1)$-oriented planes. In the $\mathrm{T}-\mathrm{L}$ orientation, the $(10 \overline{1} 0)$ and $(21 \overline{3} 0)$ planes were favored. Thus, the T-L orientation should have more elongated $\beta-\mathrm{Si}_{3} \mathrm{~N}_{4}$ grains than the $\mathrm{T}-\mathrm{S}$ orientation, consistent with microscopy observations.

\section{(2) T-S-Oriented Fracture Toughness Measurements}

$R$-curve behavior was investigated by performing short crack $(<1 \mathrm{~mm}) K_{\mathrm{IC}}$ testing at $25^{\circ}$ and $1000^{\circ} \mathrm{C}$ on T-S-oriented specimens. Long crack $(>1.4 \mathrm{~mm})$ testing was performed between $25^{\circ}$ and $1300^{\circ} \mathrm{C}$. Crack healing, a phenomena where the sharp precrack is blunted by oxidation, was also investigated on this orientation.

(A) Short Crack Fracture Toughness at $25^{\circ}$ and $100^{\circ} \mathrm{C}$ : Figure 4 is an optical micrograph of a fracture surface from an SEPB tested at $25^{\circ} \mathrm{C}$. From the figure, the initial precrack, the subsequent notch to remove the crack wake, and the fracture surface are visible. The crack length is $340 \mu \mathrm{m}$ for this sample.

Figure 5 presents $K_{\mathrm{IC}}$ as a function of crack length at $25^{\circ}$ and $1000^{\circ} \mathrm{C}$. The results indicate that no $R$-curve behavior was observed for cracks as short as $300 \mu \mathrm{m}$ at either temperature. Previous researchers have shown that the rising trend in $K_{\mathrm{IC}}$ with crack length was steeper for a small-grained $\mathrm{Si}_{3} \mathrm{~N}_{4}$ as compared to a coarser-grained $\mathrm{Si}_{3} \mathrm{~N}_{4} \cdot{ }^{3}$ In their study, a small- 

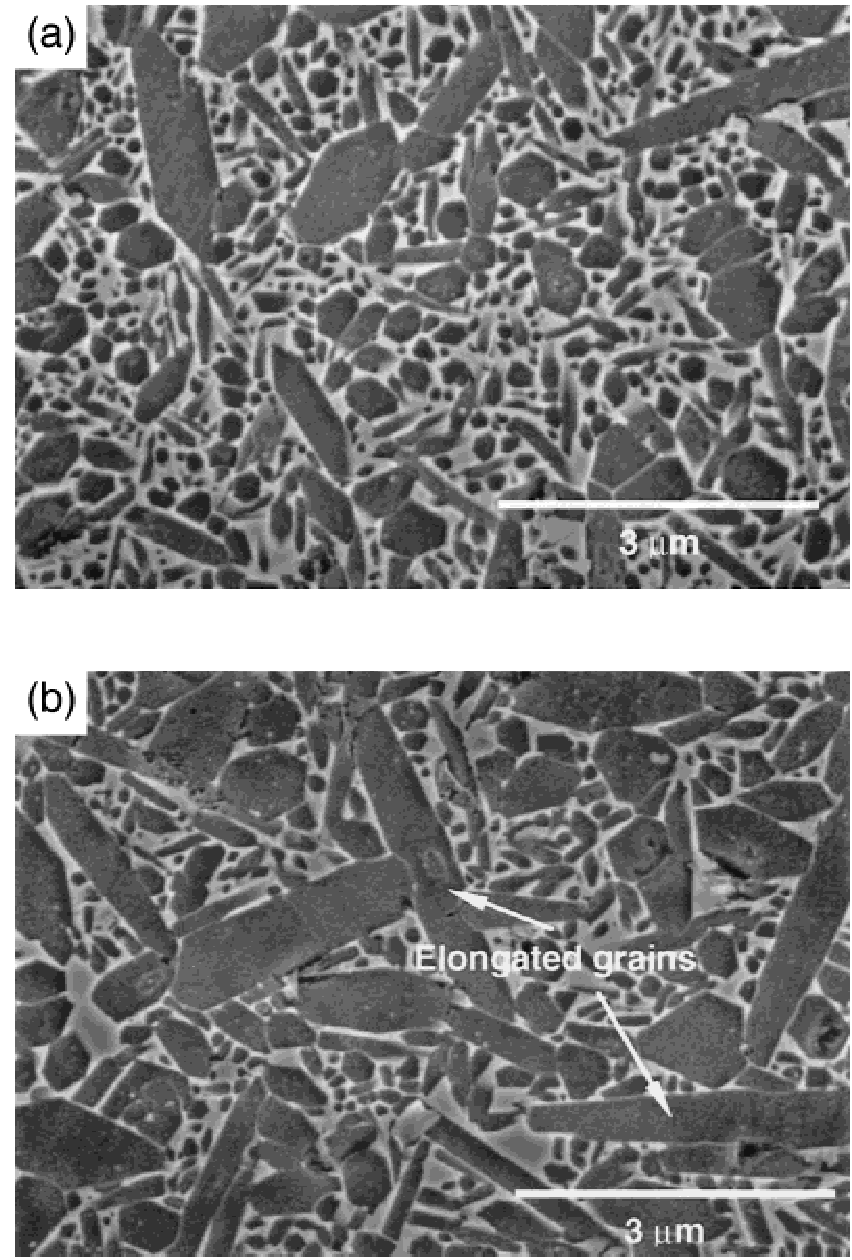

Fig. 2. SEM micrographs of plasma-etched samples indicating the microstructure of (a) T-S and (b) T-L orientations.

grained $\mathrm{Si}_{3} \mathrm{~N}_{4}$, with a $1 \mu \mathrm{m}$ diameter, demonstrated constant $K_{\text {IC }}$ at crack lengths as short as 250-350 $\mu \mathrm{m}$. For a $1.4 \mu \mathrm{m}$ diameter grain, a constant value of $K_{\mathrm{IC}}$ was observed for crack lengths of 350-450 $\mu \mathrm{m}$. Thus, coarser-grained $\mathrm{Si}_{3} \mathrm{~N}_{4}$ exhibited a longer interaction zone between the crack tip and the segment of crack wake that interacted with the microstructure. In the present study, the approximate diameter of $\mathrm{Si}_{3} \mathrm{~N}_{4}$ grains was $0.4 \mu \mathrm{m}$. Therefore, constant values of $K_{\mathrm{IC}}$ at crack lengths as short as $300 \mu \mathrm{m}$ were consistent with published data.

(B) Long Crack Fracture Toughness between $25^{\circ}$ and $1300^{\circ} \mathrm{C}$ : The temperature-dependent $K_{\mathrm{IC}}$ values in the $\mathrm{T}-\mathrm{S}$ orientation are shown in Fig. 6. All samples tested between $25^{\circ}$ and $1000^{\circ} \mathrm{C}$ were tested in air. Samples tested between $1100^{\circ}$ and $1300^{\circ} \mathrm{C}$ were tested in nitrogen to prevent the precrack from healing. A general decrease in $K_{\text {IC }}$ was observed from 6.6 $\pm 0.2 \mathrm{MPa} \cdot \mathrm{m}^{1 / 2}$ at $25^{\circ} \mathrm{C}$ to $4.1 \pm 0.4 \mathrm{MPa} \cdot \mathrm{m}^{1 / 2}$ at $1200^{\circ} \mathrm{C}$. A sharp increase in toughness was observed at $1300^{\circ} \mathrm{C}$ to $8.6 \pm$ $1.8 \mathrm{MPa} \cdot \mathrm{m}^{1 / 2}$. These trends compared well with those in the literature. ${ }^{12,13}$

(a) Toughening Mechanisms at $25^{\circ} \mathrm{C}$ : Figure 7 shows several plasma-etched T-S-oriented samples near the crack tip. Because all SEPB samples fracture into two pieces during testing, these micrographs are taken from samples that were cracked via an indentation load. Crack deflection, elastic bridging, and frictional grain bridges were observed. Figure 7(a) shows that the crack tends to be deflected around larger grains $(>0.4 \mu \mathrm{m})$, while smaller grains are cut by the crack. Furthermore, Fig. 7(b) reveals that it is energetically favorable for the crack to cut elongated $\mathrm{Si}_{3} \mathrm{~N}_{4}$ grains as wide as $0.7 \mu \mathrm{m}$ rather than be deflected by them or pull them out. Elastic bridging

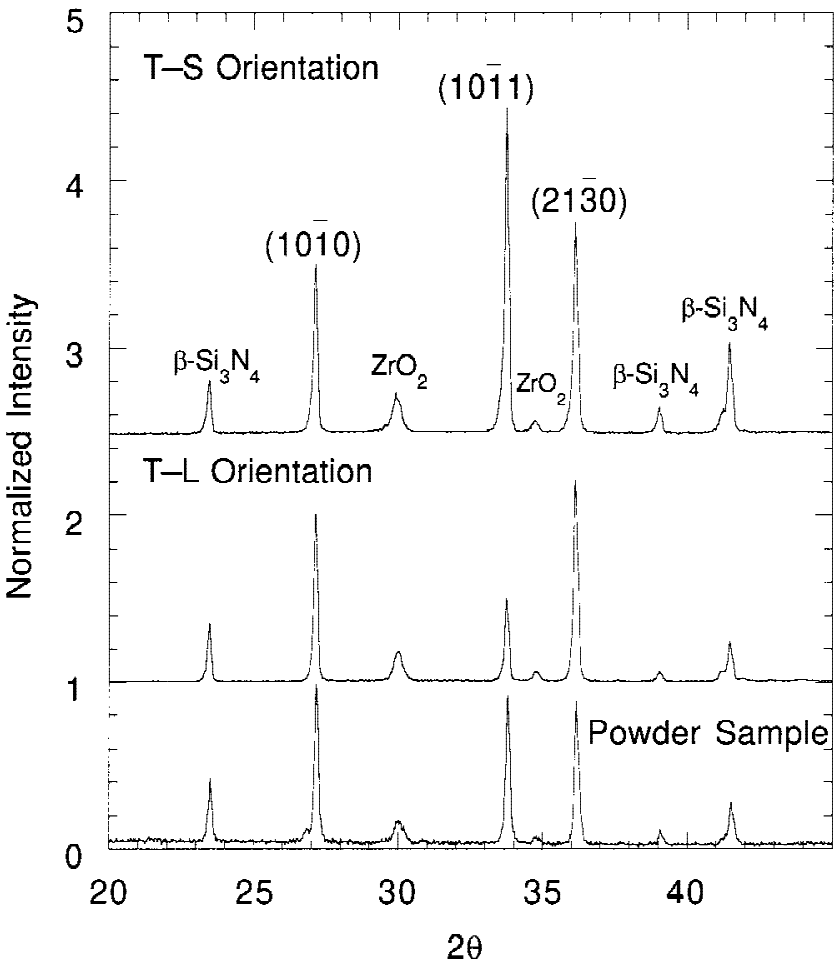

Fig. 3. Comparison of both specimen orientations to a random powder sample reveals texturing. Intensities are normalized to the (10 $\overline{1} 0)$ plane of $\beta-\mathrm{Si}_{3} \mathrm{~N}_{4}$. $\left(\mathrm{ZrO}_{2}\right.$ is a contaminant from ball milling.)

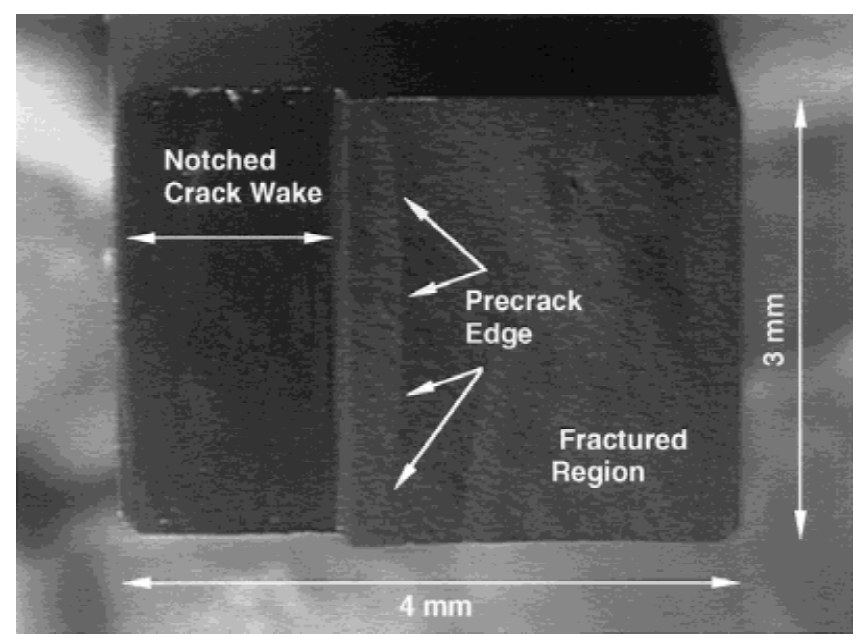

Fig. 4. Optical image of SEPB fractured at $25^{\circ} \mathrm{C}$. Original precrack, machined notch to remove the crack wake, and fracture surface are all visible.

and frictional grain bridges, as shown in Fig. 7(c), are also observed.

(b) Effect of Temperature on Toughening Mechanisms: A typical fracture surface of a T-S-oriented sample tested at $25^{\circ} \mathrm{C}$ is shown in Fig. 8(a). The fracture surface was tilted $75^{\circ}$ to reveal the surface texture. There were no $\mathrm{Si}_{3} \mathrm{~N}_{4}$ grains pulled out during fracture, consistent with Fig. 7 observations of etched samples.

As temperature was increased from $25^{\circ} \mathrm{C}$, a change in toughening mechanisms was observed. Consider Fig. 8(b), the fracture surface of a specimen tested at $800^{\circ} \mathrm{C}$, tilted at a $75^{\circ}$ angle. Large grains $(>0.8-1 \mu \mathrm{m})$ oriented perpendicular to the fracture plane were still cut by the propagating crack, as at room temperature. However, very small grains $(<0.3 \mu \mathrm{m})$ oriented 


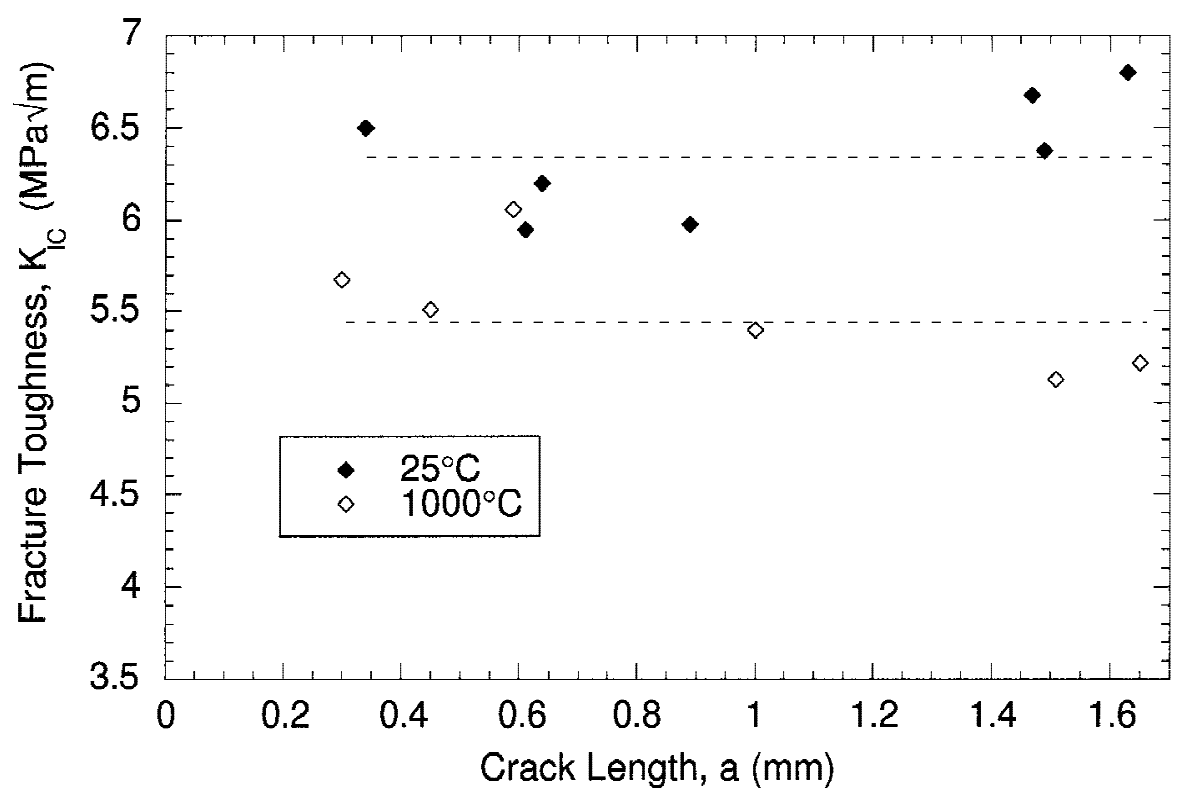

Fig. 5. Plot of $K_{\mathrm{IC}}$ as a function of crack length at $25^{\circ}$ and $1000^{\circ} \mathrm{C}$. No rising $R$-curve behavior was observed for cracks $\geq 300 \mu \mathrm{m}$.

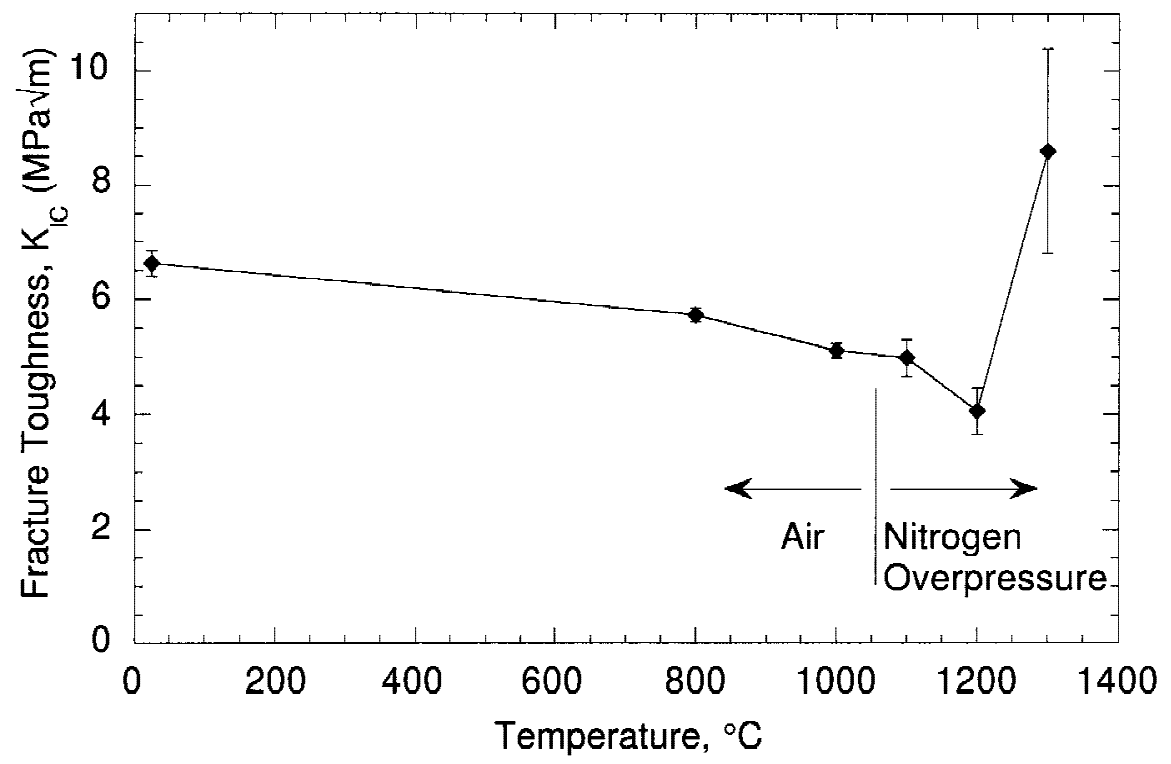

Fig. 6. $K_{\mathrm{IC}}$ of T-S-oriented samples as a function of temperature. All crack lengths were between 1.4 and $2.0 \mathrm{~mm}$.

lengthwise in the plane of fracture had been removed from the fracture surface, indicating grain pull out. Faceting of the fracture surface was observed, indicating increased crack deflection. Increased grain pull out and crack deflection at $800^{\circ} \mathrm{C}$ are believed to be the result of grain-boundary softening. ${ }^{12,13}$ As the viscosity of the amorphous glassy phase between $\mathrm{Si}_{3} \mathrm{~N}_{4}$ grains decreased, it was easier for the crack to separate individual grains rather than cut them.

Figure 8(c) reveals the typical fracture surface of a specimen tested in nitrogen at $1200^{\circ} \mathrm{C}$. Faceting of the surface is observed similar to those samples tested at $800^{\circ} \mathrm{C}$, with extensive pull out observed for grains $\leq 0.6 \mu \mathrm{m}$. The failure surface observations made on samples tested at $1200^{\circ} \mathrm{C}$ are consistent with continued softening of the amorphous grain-boundary phase. The initial consequence of grain-boundary softening is decreased $K_{\mathrm{IC}}$, as observed in Fig. 6 .

(c) Toughness Behavior at $1300^{\circ} \mathrm{C}$ in a Nitrogen Environment: Stable crack growth was observed only in specimens tested at $1300^{\circ} \mathrm{C}$. This is revealed in the microstructure, as shown in Fig. 9. The surface texture reveals three distinct regions. Region I is the initial precrack that was created at room temperature, while regions II and III are the areas of stable and unstable crack extension, respectively.

Region II behavior indicates that cracks in $\mathrm{Si}_{3} \mathrm{~N}_{4}$ at $1300^{\circ} \mathrm{C}$ can grow slowly under applied stress intensity values well below the critical stress intensity. For example, a stress intensity of $6.7 \pm 1.7 \mathrm{MPa} \cdot \mathrm{m}^{1 / 2}$ initiates crack growth at this temperature, but a stress intensity of $8.6 \pm 1.8 \mathrm{MPa} \cdot \mathrm{m}^{1 / 2}$ is ultimately required for fracture. Region II behavior has been observed previously ${ }^{13}$ and was attributed to reorientation of individual grains of $\mathrm{Si}_{3} \mathrm{~N}_{4}$ under the imposed tensile stresses. Figure 10 is a comparison of region II and region III fracture surfaces. In both micrographs, extensive crack deflection and pull out are observed.

(C) Fracture Energy as a Function of Temperature: The fracture energy of $\mathrm{Si}_{3} \mathrm{~N}_{4}, \Gamma_{\mathrm{SN}}$, as a function of temperature in 

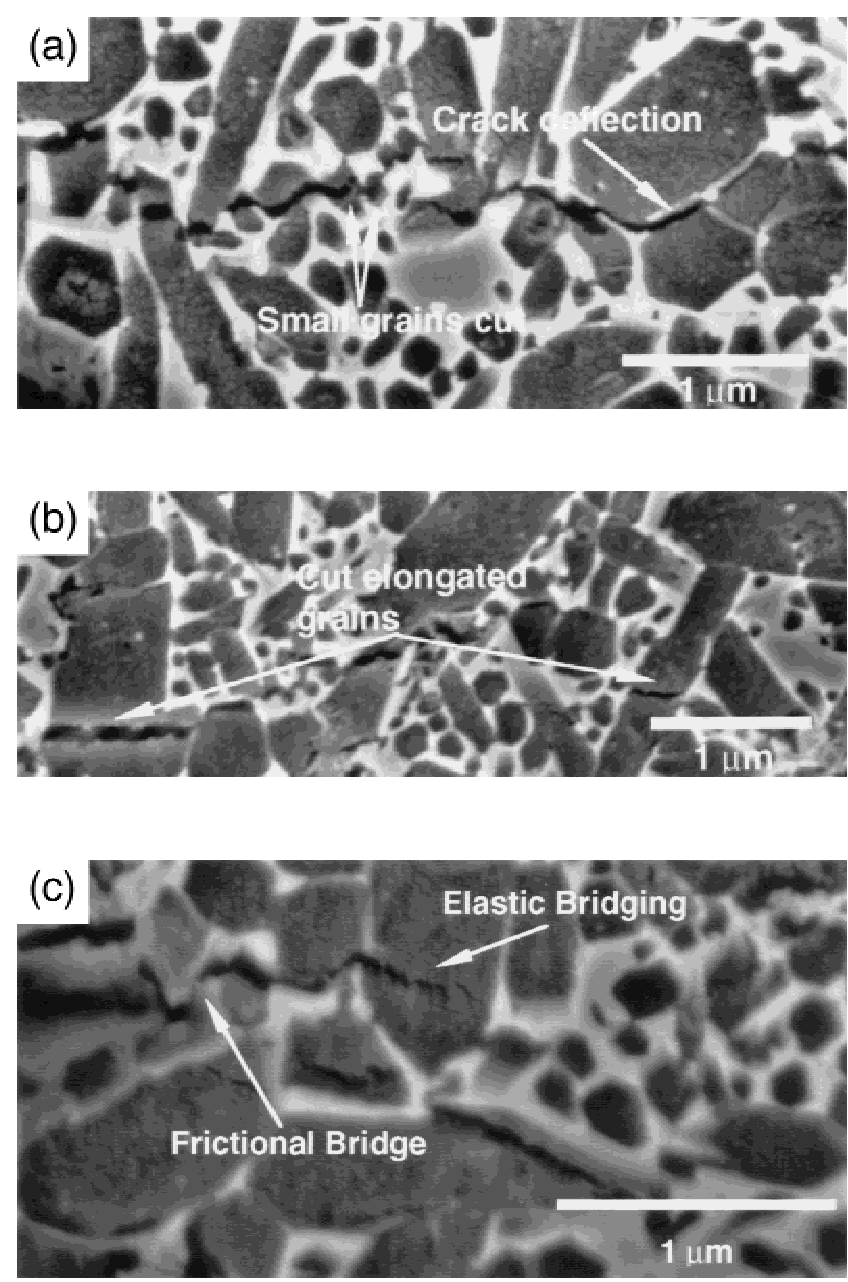

\section{Crack Propagation Direction}

Fig. 7. Plasma-etched micrographs of samples in the T-S orientation near the edge of the crack tip. These samples were tested at $25^{\circ} \mathrm{C}$. Crack deflection, elastic bridging, and frictional grain bridges were observed.

the $\mathrm{T}-\mathrm{S}$ orientation was calculated using the long crack $K_{\mathrm{IC}}$ values presented in Fig. 6 . $\Gamma_{\mathrm{SN}}$ was calculated using the plane strain equation relating fracture energy to $K_{\mathrm{IC}}$

$$
\Gamma_{\mathrm{SN}}=K_{\mathrm{IC}}^{2}\left(1-v^{2}\right) / E
$$

where $v$ was Poisson's ratio, and $E$ the longitudinal Young's modulus, varied for each temperature of interest. Poisson's ratio for $\mathrm{Si}_{3} \mathrm{~N}_{4}$ was assumed to be constant with temperature and equal to $0.27 .{ }^{21}$ The change in modulus with temperature ${ }^{22}$ for this composition of $\mathrm{Si}_{3} \mathrm{~N}_{4}$ is presented in Table I. The calculated results are plotted in Fig. 11.

Fracture energy at $25^{\circ} \mathrm{C}$ is $129 \pm 9 \mathrm{~J} / \mathrm{m}^{2}$, which compares well with literature values. ${ }^{23}$ The fracture energy decreases to $100 \pm 5 \mathrm{~J} / \mathrm{m}^{2}$ at $800^{\circ} \mathrm{C}$ and remains essentially constant through $1100^{\circ} \mathrm{C}$. A significant drop in $\Gamma_{\mathrm{SN}}$ is observed at $1200^{\circ} \mathrm{C}$, to $65 \pm 15 \mathrm{~J} / \mathrm{m}^{2}$, before rapidly increasing to $390 \pm 150 \mathrm{~J} / \mathrm{m}^{2}$ at $1300^{\circ} \mathrm{C}$. The mechanistic reasons for the decrease and then increase in $\Gamma_{\mathrm{SN}}$ have been attributed to softening of the glassy phase and reorientation of the elongated $\mathrm{Si}_{3} \mathrm{~N}_{4}$ grains, respectively. ${ }^{13}$

(D) Fracture Toughness as a Function of Testing Atmosphere: Crack healing, the process where a sharp crack blunts because of oxidation, has been observed by Choi and Tikare ${ }^{24}$
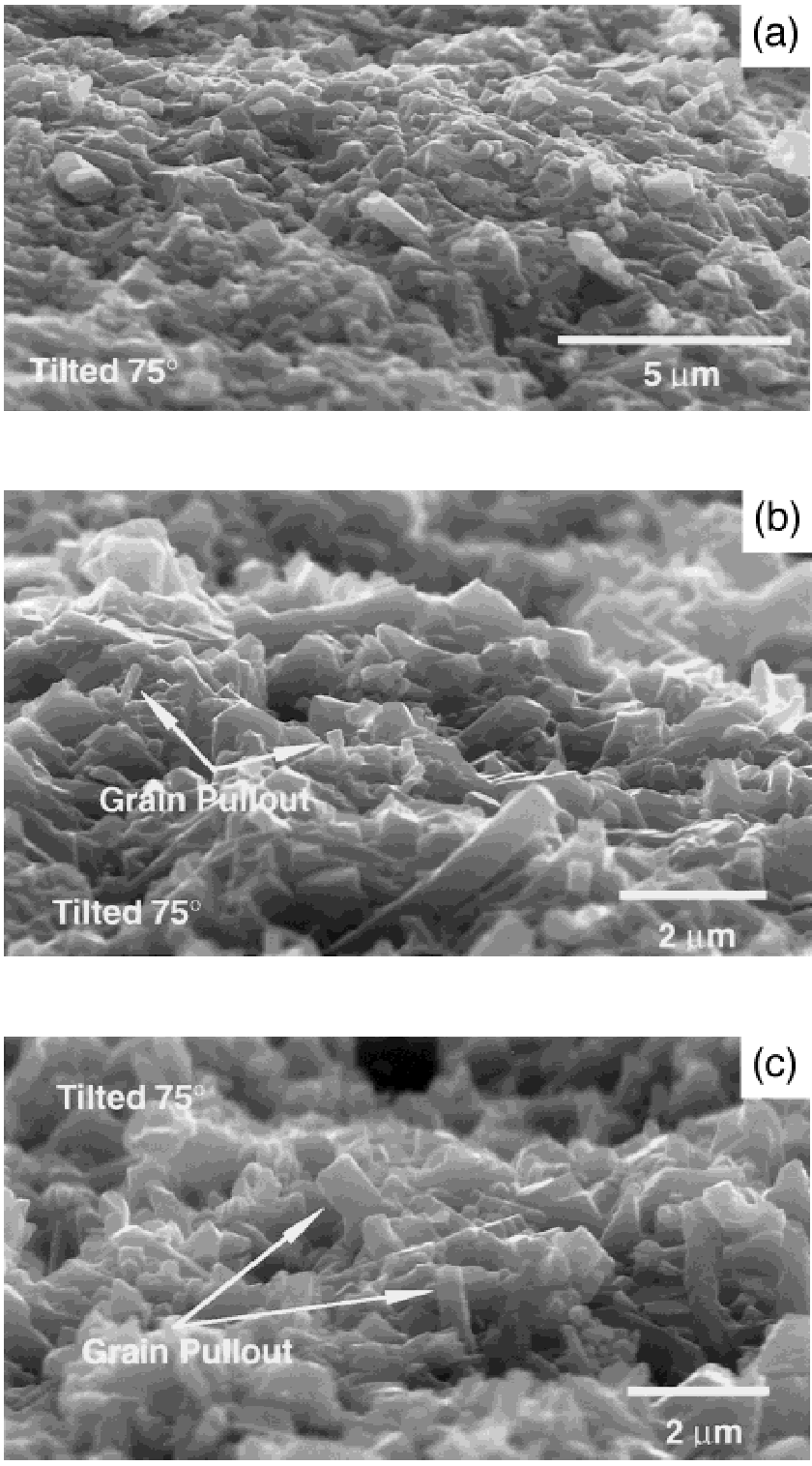

Fig. 8. Typical fracture surfaces of T-S-oriented SEPB specimen tested at (a) $25^{\circ}$, (b) $800^{\circ}$, and (c) $1200^{\circ} \mathrm{C}$. In each micrograph, the specimen was tilted $75^{\circ}$ to reveal the texture of the surface. Large grains of $\mathrm{Si}_{3} \mathrm{~N}_{4}$ were pulled out during fracture at both $800^{\circ}$ and $1200^{\circ} \mathrm{C}$.

in hot-pressed $\mathrm{Si}_{3} \mathrm{~N}_{4}$ sintered with $\mathrm{MgO}$. In their study, the authors showed that a sample annealed in air for $30 \mathrm{~min}$ at $800^{\circ} \mathrm{C}$ demonstrated a marked increase in $K_{\text {IC }}$ upon cooling to $25^{\circ} \mathrm{C}$ and testing, as compared to an unannealed specimen. With XRD, it was shown that the precrack was filled with two oxidation products, enstatite and cristobalite. Thus, the crack tip was no longer sharp, a necessary condition for a valid $K_{\mathrm{IC}}$ measurement.

The crack healing phenomena for a more refractory composition of $\mathrm{Si}_{3} \mathrm{~N}_{4}$ was investigated in this series of experiments, where precracked SEPB samples were heated in $1 \mathrm{~h}$ to temperatures ranging from $1000^{\circ}$ through $1300^{\circ} \mathrm{C}$ in air or nitrogen, held for $10 \mathrm{~min}$, then furnace cooled. The annealed specimens were then tested at ambient temperatures. These results were compared to those for unannealed specimens tested at $25^{\circ} \mathrm{C}$, as shown in Fig. 12. All crack lengths were $>1.4 \mathrm{~mm}$.

The unannealed specimens demonstrated a $K_{\text {IC }}$ of $6.6 \pm 0.2$ $\mathrm{MPa} \cdot \mathrm{m}^{1 / 2}$. The specimens annealed in a nitrogen environment at temperatures between $1100^{\circ}$ and $1300^{\circ} \mathrm{C}$ and tested at $25^{\circ} \mathrm{C}$ 


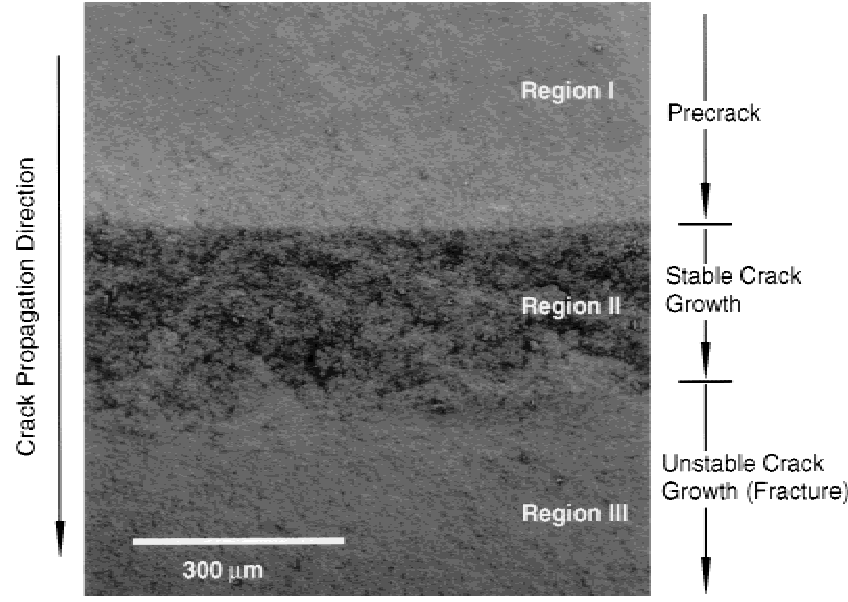

Fig. 9. T-S-oriented fracture surface at $1300^{\circ} \mathrm{C}$ for a specimen tested in nitrogen. Three distinct regions were observed.

demonstrated a toughness between 6.3 and $6.7 \mathrm{MPa} \cdot \mathrm{m}^{1 / 2}$, essentially unchanged by the heat treatment.

No significant change in toughness was observed for a specimen annealed in air at $1100^{\circ} \mathrm{C}$. However, the microstructure near the crack tip exhibited an oxidation product. This product was more easily identified as annealing temperature increased. At annealing temperatures of $1200^{\circ}$ and $1300^{\circ} \mathrm{C}$, the apparent $K_{\mathrm{IC}}$ increased to 7.6 and $11.2 \mathrm{MPa} \cdot \mathrm{m}^{1 / 2}$, respectively. Clearly, the precrack was blunted by the newly created oxidation phase.

Figure 13 reveals the fracture surface of a specimen annealed at $1300^{\circ} \mathrm{C}$ in air and subsequently tested at $25^{\circ} \mathrm{C}$, revealing an oxidation product existing behind the original tip of the precrack. SEM investigation of this area revealed a glazed surface. Previous research on a similar composition of $\mathrm{Si}_{3} \mathrm{~N}_{4}{ }^{25}$ indicated that the final phases formed during oxidation are cristobalite and yttrium silicate.

\section{(3) Effect of Hot-Pressing Orientation on Toughening Mechanisms and Fracture Toughness}

The toughening mechanisms observed in the T-L orientation at room temperature were similar to those observed in the T-S orientation. Crack deflection was generally observed for grains
Table I. Measured Values of Flexural Modulus as a Function of Temperature for Silicon Nitride ${ }^{\dagger}$

\begin{tabular}{cc}
\hline Temperature $\left({ }^{\circ} \mathrm{C}\right)$ & Modulus $(\mathrm{GPa})$ \\
\hline 25 & $316 \pm 16$ \\
800 & $304 \pm 15$ \\
900 & $298 \pm 15$ \\
1000 & $247 \pm 12$ \\
1100 & $237 \pm 12$ \\
1200 & $235 \pm 12$ \\
1300 & $177 \pm 9$ \\
\hline${ }_{\text {aids. }}^{22}{ }^{\dagger t} \% \mathrm{Y}_{2} \mathrm{O}_{3}$ and $2 \mathrm{wt} \% \mathrm{Al}_{2} \mathrm{O}_{3}$ added as sintering
\end{tabular}

$>0.4 \mu \mathrm{m}$, with elastic and frictional bridges also observed. As in the T-S orientation, fiber pullout was not observed.

The long crack $K_{\text {IC }}$ data with respect to orientation and temperature are plotted in Fig. 14. The measured toughness in the $\mathrm{T}-\mathrm{L}$ orientation at $25^{\circ} \mathrm{C}$ was $5.9 \pm 0.1 \mathrm{MPa} \cdot \mathrm{m}^{1 / 2}$. This value remained essentially constant through $800^{\circ} \mathrm{C} . K_{\mathrm{IC}}$ values of $5.0 \pm 0.1$ and $5.1 \pm 0.1 \mathrm{MPa} \cdot \mathrm{m}^{1 / 2}$ were measured at $1000^{\circ}$ and $1100^{\circ} \mathrm{C}$, respectively. A sharp decrease in $K_{\mathrm{IC}}$ was observed near $1200^{\circ} \mathrm{C}$ to $4.2 \pm 0.01 \mathrm{MPa} \cdot \mathrm{m}^{1 / 2}$, before increasing to $7.7 \pm 2.4 \mathrm{MPa} \cdot \mathrm{m}^{1 / 2}$ at $1300^{\circ} \mathrm{C}$.

$K_{\mathrm{IC}}$ at ambient temperatures was $6.6 \pm 0.2$ and $5.9 \pm 0.1$ $\mathrm{MPa} \cdot \mathrm{m}^{1 / 2}$ for the $\mathrm{T}-\mathrm{S}$ and $\mathrm{T}-\mathrm{L}$ orientations, respectively. It is proposed that subtle differences in texturing are responsible for the difference in toughness at room temperature. As shown previously, XRD results indicate that the $(10 \overline{1} 0)$ and $(21 \overline{3} 0)$ planes are favored for diffraction in the $\mathrm{T}-\mathrm{L}$ orientation. In terms of the microstructure of the sample, this implies that more of the grains have oriented themselves lengthwise on the surface. Figure 7 shows that the crack path typically cuts these elongated grains without changing its direction. The result is that the crack path is straighter for the $\mathrm{T}-\mathrm{L}$ orientation, and thus the crack tip is not as well shielded as in the T-S orientation. For this reason, the measured toughness should be lower.

It is important to point out that these results would likely only be true for a small-grained $\mathrm{Si}_{3} \mathrm{~N}_{4}$, as is the case here. If the width of the elongated grains were $>2-3 \mu \mathrm{m}$, it might be expected that the $\mathrm{T}-\mathrm{L}$ orientation would demonstrate the highest toughness. In this case, the crack tip could no longer fracture
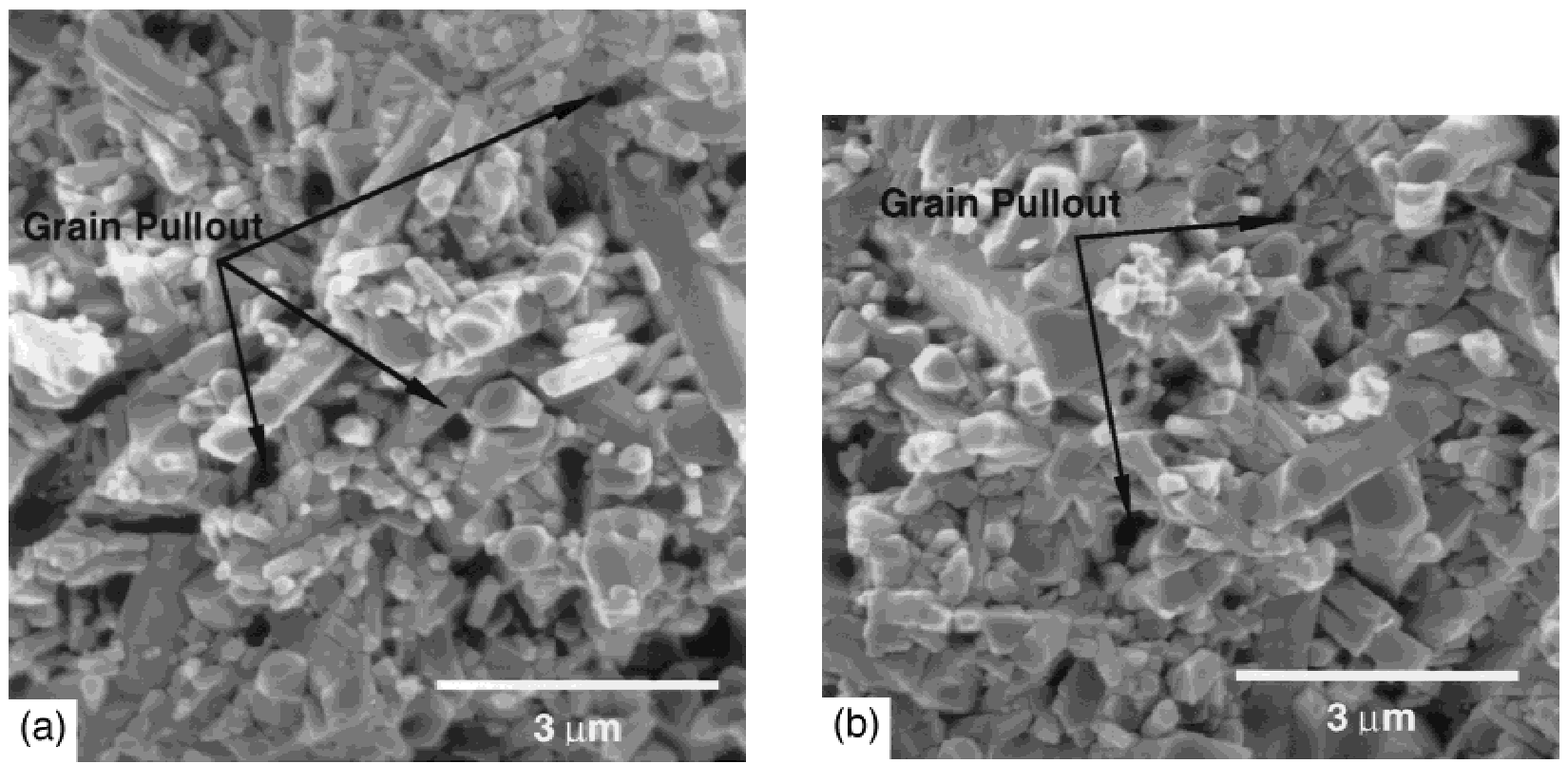

Fig. 10. Comparison of fracture surfaces from specimens tested at $1300^{\circ} \mathrm{C}$ in (a) region II (stable crack growth) and (b) region III (unstable crack growth) in the T-S orientation. Extensive crack deflection and grain pull out were observed in both. 


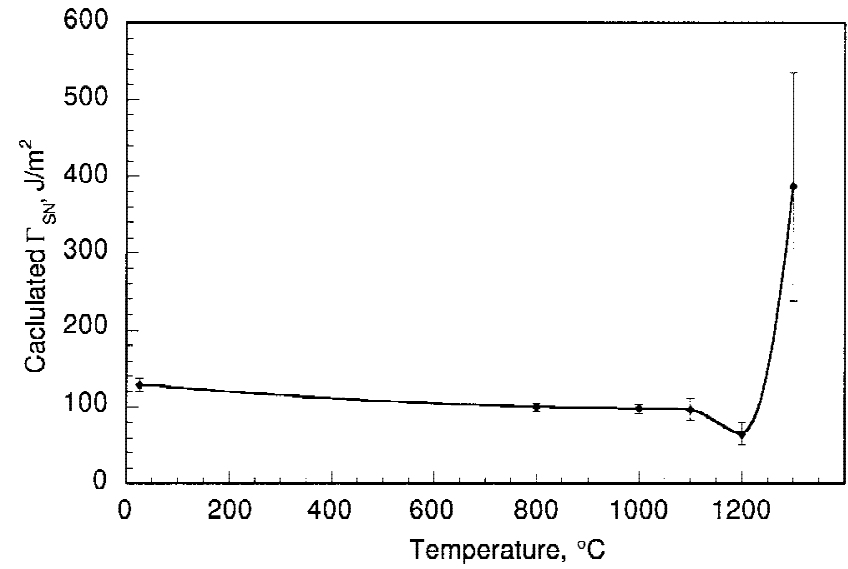

Fig. 11. Fracture energy, $\Gamma_{\mathrm{SN}}$, in the $\mathrm{T}-\mathrm{S}$ orientation as a function of temperature.

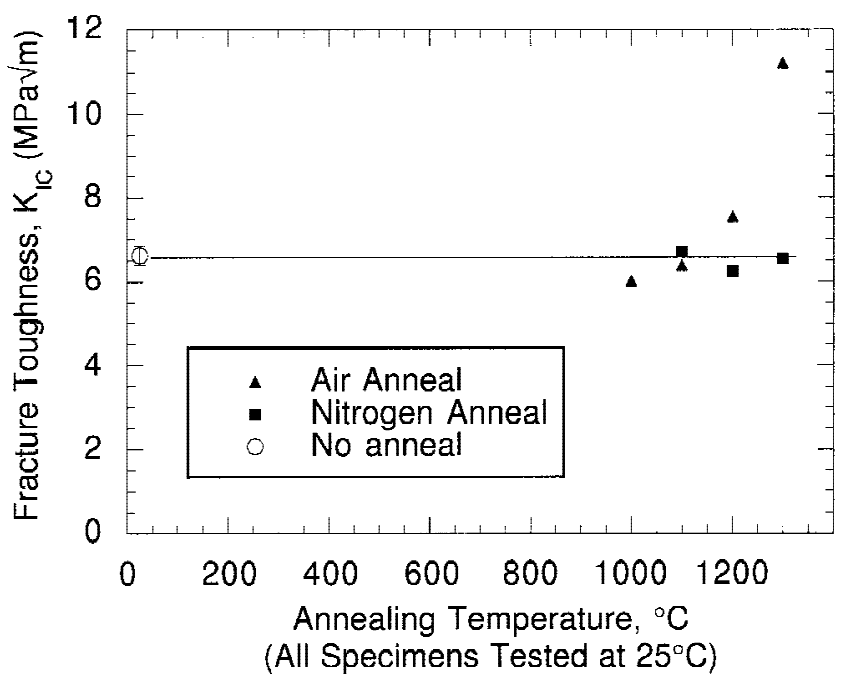

Fig. 12. $K_{\mathrm{IC}}$ as a function of anneal temperature in air for the T-S orientation. Samples annealed in air showed evidence of crack healing, beginning at $1100^{\circ} \mathrm{C}$, with marked increases in toughness observed at $1200^{\circ}$ and $1300^{\circ} \mathrm{C}$.

the elongated grain but, rather, must follow the grain boundary during fracture. This would lead to an increase in toughness because of grain pullout.

At $\geq 800^{\circ} \mathrm{C}$, the two orientations converge essentially to the same toughness values. As was shown previously, crack deflection and grain pull out become the dominant mechanisms at these temperatures. Thus, the crack path for both orientations is similar, resulting in roughly equivalent toughness values.

\section{Conclusions}

$K_{\text {IC }}$ of a small-grain $\mathrm{Si}_{3} \mathrm{~N}_{4}$, with $6 \mathrm{wt} \% \quad \mathrm{Y}_{2} \mathrm{O}_{3} / 2 \mathrm{wt} \% \quad \mathrm{Al}_{2} \mathrm{O}_{3}$ sintering aids, has been determined as a function of orientation, temperature, testing atmosphere, and crack length using singleedge precracked beams.

Subtle changes in toughness at ambient temperature as a function of hot-pressing orientation were attributed to the amount of elongated $\beta-\mathrm{Si}_{3} \mathrm{~N}_{4}$ grains present in the plane of crack growth. For both orientations at ambient temperature, the toughening mechanisms observed included crack deflection, elastic bridging, and frictional bridging.

The $K_{\mathrm{IC}}$ in both orientations continually decreased upon heating through $1200^{\circ} \mathrm{C}$, to $\sim 4.1 \mathrm{MPa} \cdot \mathrm{m}^{1 / 2}$, before increasing rapidly to $7.5-8 \mathrm{MPa} \cdot \mathrm{m}^{1 / 2}$ at $1300^{\circ} \mathrm{C}$. Between $800^{\circ}-1200^{\circ} \mathrm{C}$,

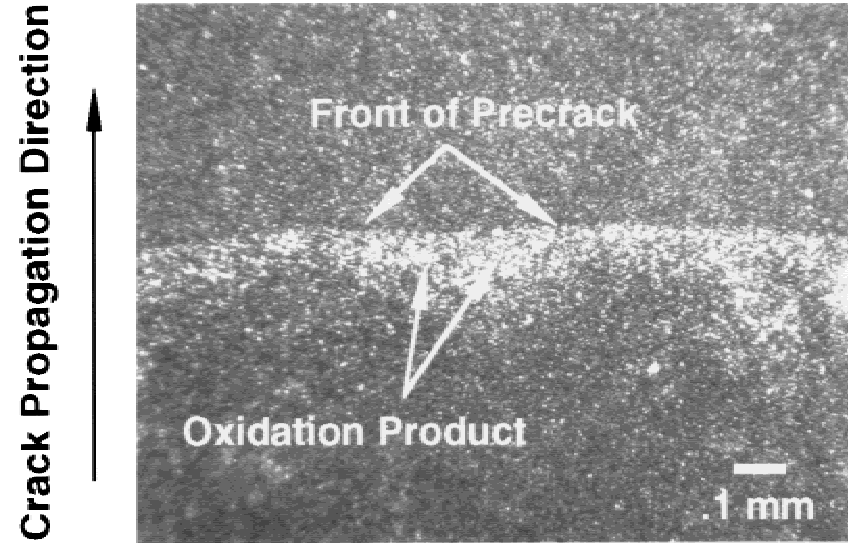

Fig. 13. Fracture surface of a sample annealed at $1300^{\circ} \mathrm{C}$ in air then tested at room temperature. An oxidation product was observed behind the original precrack.

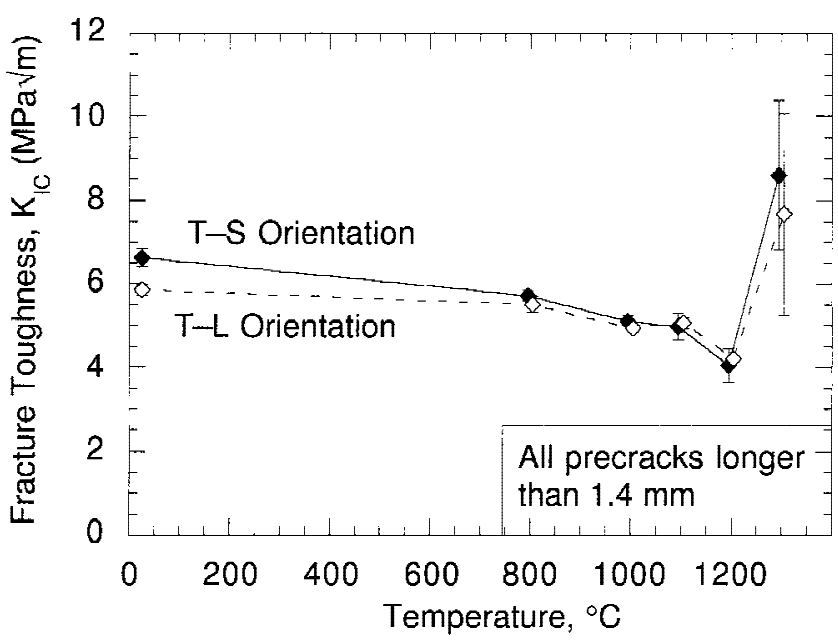

Fig. 14. Plot of $K_{\mathrm{IC}}$ as a function of temperature for both orientations investigated. Some of the data points have been offset slightly for clarity.

softening of the grain-boundary glassy phase led to increased crack deflection and grain pull out, as compared with samples tested at $25^{\circ} \mathrm{C}$. At $1300^{\circ} \mathrm{C}$, stable crack growth was observed. Reorientation of elongated grains in the direction of the applied load was suggested to explain the increase in $K_{\mathrm{IC}}$ in this region. Crack healing was observed in specimens tested in air, indicating that the single-edge precracked beam method should be used with caution for $\mathrm{Si}_{3} \mathrm{~N}_{4}$ at elevated temperatures. This effect began at $1100^{\circ}$, but was most pronounced at $1200^{\circ}$ and $1300^{\circ} \mathrm{C}$ for this particular composition of $\mathrm{Si}_{3} \mathrm{~N}_{4}$.

Acknowledgment: The authors wish to thank Anatoly Rosenflanz for assistance with part of the high-temperature testing.

\section{References}

${ }^{1}$ R. Knehans and R. Steinbrech, "Memory Effect of Crack Resistance During Slow Crack Growth in Notched $\mathrm{Al}_{2} \mathrm{O}_{3}$ Bend Specimens," J. Mater. Sci. Lett., 1 , 327-29 (1982).

${ }^{2}$ N. Ramachandran and D. K. Shetty, "Rising Crack-Growth-Resistance $(R-$ Curve) Behavior of Toughened Alumina and Silicon Nitride," J. Am. Ceram. Soc., 74 [10] 2634-41 (1991).

${ }^{3}$ C. W. Li, D. J. Lee, and S. C. Lui, " $R$-Curve Behavior and Strength for In-Situ Reinforced Silicon Nitride with Different Microstructures," J. Am. Ceram. Soc., 75 [7] 1777-85 (1992).

${ }^{4}$ J. B. Wachtman, Mechanical Properties of Ceramics; p. 142. Wiley, New York, 1996.

${ }^{5}$ A. G. Evans, "Perspective on the Development of High-Toughness Ceramics," J. Am. Ceram. Soc., 73 [2] 187-206 (1990). 
${ }^{6} \mathrm{~F}$. F. Lange, "Fracture Toughness of $\mathrm{Si}_{3} \mathrm{~N}_{4}$ as a Function of the Initial

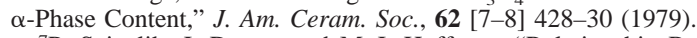

${ }^{7}$ P. Sajgalik, J. Dusza, and M. J. Hoffman, "Relationship Between Microstructure, Toughening Mechanisms, and Fracture Toughness of Reinforced Silicon Nitride Ceramics," J. Am. Ceram. Soc., 78 [10] 2619-24 (1995).

${ }^{8}$ C.-W. Li, S.-C. Lui, and J. Goldacker, "Relation Between Strength, Microstructure, and Grain Bridging Characteristics in In-Situ Reinforced Silicon Nitride," J. Am. Ceram. Soc., 78 [2] 449-59 (1995).

${ }^{9}$ Y. W. Kim, M. Mitomo, and N. Hirosaki, " $R$-curve Behavior of Sintered Silicon Nitride," J. Mater. Sci., 30, 4043-48 (1995).

${ }^{10} \mathrm{~T}$. Ohji, K. Hirao, and S. Kanzaki, "Fracture Resistance Behavior of Highly Anisotropic Silicon Nitride," J. Am. Ceram. Soc., 78 [11] 3125-28 (1995).

${ }^{11}$ E. Tani, S. Umebayashi, K. Kishi, K. Kobayashi, and M. Nishijima, "Effect of Size of Grains with Fiber-Like Structure of $\mathrm{Si}_{3} \mathrm{~N}_{4}$ on Fracture Toughness," $J$. Mater. Sci., 4, 1454-56 (1985).

${ }^{12}$ A. A. Wereszczak, M. K. Ferber, R. R. Sanders, M. G. Jenkins, and P. Khandelwal, "Fracture Toughness of a HIPed $\mathrm{Si}_{3} \mathrm{~N}_{4}$ at Elevated Temperatures," Ceram. Eng. Sci. Proc., 14 [7-8] 101-12 (1993).

${ }^{13}$ Y. Mutoh, K. Yamaishi, N. Miyahara, and T. Oikawa, "Brittle-to-Ductile Transition in Silicon Nitride" pp. 427-40 in Fracture Mechanics of Ceramics, Vol. 10. Edited by R. C. Brady, D. P. H. Hasselman, D. Munz, M. Sakai, and V. Ya. Shevchenko. Plenum Press, New York, 1992.

${ }^{14}$ G. D. Quinn, J. Salem, I. Bar-on, and K. Cho, M. Foley, and H. Fang, "Fracture Toughness of Advanced Ceramics at Room Temperature," J. Res. Natl. Inst. Stand. Technol., 97, 579-607 (1992).

15"Standard Test Methods for the Determination of Fracture Toughness of Advanced Ceramics at Ambient Temperatures," ASTM Provisional Standard Designation No. PS070-97. American Society for Testing and Materials, West Conshohocken, PA.
${ }^{16}$ M. Mizuno and H. Okuda, "VAMAS Round Robin on Fracture Toughness of Silicon Nitride,” J. Am. Ceram. Soc., 78 [7] 1793-801 (1995).

${ }^{17}$ R. Steinbrech, R. Khenans, and W. Schaarwachter, "Increase of Crack Resistance During Slow Crack Growth in $\mathrm{Al}_{2} \mathrm{O}_{3}$ Bend Specimens," J. Mater. Sci., 18, 265-70 (1983).

18“Standard Test Method for Water Absorption, Bulk Density, Apparent Porosity, and Apparent Specific Gravity of Fired Whiteware Products," ASTM Designation C373-88. American Society for Testing and Materials, West Conshohocken, PA.

19'"Standard Test Method for Dynamic Young's Modulus, Shear Modulus, and Poisson's Ratio for Advanced Ceramics by Sonic Resonance," ASTM Designation C1198-96. American Society for Testing and Materials, West Conshohocken, PA.

${ }^{20}$ Powder Diffraction File, Card No. 33-1160. International Centre for Diffraction Data, Newtown Square, PA.

${ }^{21}$ S. Hampshire, "Nitride Ceramics"; pp. 814-20 in Engineered Materials Handbook, Vol. 4, Ceramics and Glasses. ASM International, Metals Park, OH, 1991.

${ }^{22}$ R. W. Trice and J. W. Halloran, "The Elevated Temperature Mechanical Properties of Silicon Nitride/Boron Nitride Fibrous Monolithic Ceramics," J. Am. Ceram. Soc., in press.

${ }^{23}$ Y. Mutoh, N. Miyahara, K. Yamaishi, and T. Oikawa, "High-Temperature Fracture Toughness in Silicon Nitride," J. Eng. Mater. Technol., 115 [7] 268-72 (1993)

${ }^{24}$ S. R. Choi and V. Tikare, "Crack Healing Behavior of Hot-Pressed Silicon Nitride Due to Oxidation," Scr. Metall. Mater., 26, 1263-68 (1992).

${ }^{25}$ Y. G. Gogotsi, G. Grathwohl, F. Thummler, V. P. Yaroshenko, M. Herrmann, and C. Taut, "Oxidation of Yttria- and Alumina-Containing Dense Silicon Nitride Ceramics,” J. Eur. Ceram. Soc., 11, 375-86 (1993). 